Check for updates

Cite this: RSC Adv., 2019, 9, 21363

Received 26th May 2019

Accepted 1st July 2019

DOI: $10.1039 / c 9 r a 03975 a$

rsc.li/rsc-advances

\section{Layered metal-organic framework based on tetracyanonickelate as a cathode material for in situ Li-ion storage $\uparrow$}

\author{
Kaiqiang Zhang, ${ }^{\text {ab }}$ Tae Hyung Lee, ${ }^{a}$ Bailey Bubach, ${ }^{c}$ Mehdi Ostadhassan, (D) *c \\ Ho Won Jang, (DD *a Ji-Won Choi ${ }^{\star b}$ and Mohammadreza Shokouhimehr (D) *ac
}

Prussian blue analogs (PBAs) formed with hexacyanide linkers have been studied for decades. The framework crystal structure of PBAs mainly benefits from the six-fold coordinated cyano functional groups. In this study, in-plane tetracyanonickelate was utilized to engineer an organic linker and design a family of four-fold coordinated PBAs (FF-PBAs; $\mathrm{Fe}^{2+} \mathrm{Ni}(\mathrm{CN})_{4}, \mathrm{MnNi}(\mathrm{CN})_{4}, \mathrm{Fe}^{3+} \mathrm{Ni}(\mathrm{CN})_{4}, \mathrm{CuNi}(\mathrm{CN})_{4}$,

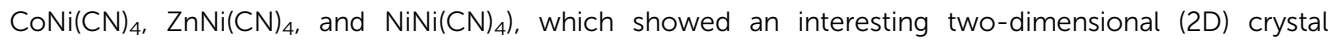
structure. It was found that these FF-PBAs could be utilized as cathode materials of Li-ion batteries, and the $\mathrm{Ni} / \mathrm{Fe}^{2+}$ system exhibited superior electrochemical properties compared to the others with a capacity of $137.9 \mathrm{~mA} \mathrm{~h} \mathrm{~g}^{-1}$ at a current density of $100 \mathrm{~mA} \mathrm{~g}^{-1}$. Furthermore, after a 5000 -cycle long-term repeated charge/discharge measurement, the $\mathrm{Ni} / \mathrm{Fe}^{2+}$ system displayed a capacity of $60.3 \mathrm{~mA} \mathrm{~h} \mathrm{~g}^{-1}$ with a coulombic efficiency of $98.8 \%$ at a current density of $1000 \mathrm{~mA} \mathrm{~g}^{-1}$. In addition, the capacity of $86.1 \%$ was preserved at $1000 \mathrm{~mA} \mathrm{~g}^{-1}$ as compared with that at $100 \mathrm{~mA} \mathrm{~g}^{-1}$, implying a good rate capability. These potential capacities can be ascribed to an in situ reduction of $\mathrm{Li}^{+}$in the interlayer of $\mathrm{Ni} / \mathrm{Fe}^{2+}$ instead of the formation of other compounds with the host material according to ex situ XRD characterization. These specially designed FF-PBAs are expected to inspire new concepts in electrochemistry and other applications requiring 2D materials.

\section{Introduction}

Prussian blue analogs (PBAs) are intriguing metal-organic framework (MOF) materials and are expected to be utilized on a large-scale for various applications due to their reasonable cost, facile and environment-friendly synthesis, and possession of attractive properties such as electrochemical, gas absorption, and electrochromic, etc. ${ }^{\mathbf{1 - 4}}$ To date, dozens of PBAs and their applications have been reported. Face-centered cubic crystal structures of PBAs are formed by the cyanide linker alternately and six-fold bridging with single or different transition metal ions. The frameworks formed in the PBAs impart attractive absorption properties, which enable applications requiring high specific area and encapsulation capability such as gas absorption, ${ }^{5}$ metal ion absorption in batteries, etc. ${ }^{6-9}$ The present precursors for the formation of PBAs are mainly based

${ }^{a}$ Department of Materials Science and Engineering, Seoul National University, Seoul 08826, Republic of Korea.E-mail: hwjang@snu.ac.kr; mrsh2@snu.ac.kr

${ }^{b}$ Electronic Materials Center, Korea Institute of Science and Technology (KIST), Seoul 136-791, Republic of Korea. E-mail: jwchoi@kist.re.kr

'Department of Petroleum Engineering, University of North Dakota, Grand Forks, ND 58202, USA. E-mail: Mehdi.Ostadhassan@und.edu

$\dagger$ Electronic supplementary information (ESI) available. See DOI: 10.1039/c9ra03975a on hexacyano salts. ${ }^{\mathbf{1 0} 11}$ The cyanide-based MOFs are more attractive than any other type of MOFs that require an increased cost and/or complex synthesis (e.g., hydrothermal), together with the inherent contaminated nature of the organic reactants employed during the synthetic processes. ${ }^{12,13}$

The PBAs demonstrate tunable electrochemical properties owing to the framework-shaped crystal structure. ${ }^{14}$ The various reports on PBAs being used as electrode materials of electrochemical batteries reveal their stable electrochemical behaviors in diverse battery systems, including metal-ion batteries (e.g., Li-, Na-, K-, Al-ion batteries) and metal-air batteries. ${ }^{15-19}$ For example, Lee et al. used vanadium hexacyanoferrate-based PBA as an electrode material for aqueous batteries and achieved a significantly improved capacity by unprecedented dual-ion redox reactions. ${ }^{20}$ PBAs are also promising as electrode materials in non-aqueous electrolyte-based battery systems. Deng et al. employed $\mathrm{PBA} \mathrm{Co}_{3}\left[\mathrm{Co}(\mathrm{CN})_{6}\right]_{2}$ as an anode material for $\mathrm{K}$ ion batteries. It was found that this PBA displays a high capacity owing to the solid-state diffusion-limited potassiation/ depotassiation processes. ${ }^{21}$ Instead of directly using the PBAs as electrode materials, Lee et al. studied the porous spinel oxides derived from $\mathrm{Mn}_{3}\left[\mathrm{Co}(\mathrm{CN})_{6}\right]_{2}$ serving as electrode material for $\mathrm{Zn}$-air batteries. ${ }^{22}$ In addition, the cavities inside the PBAs were also shown to be capable of capacitive metal-ion storage. ${ }^{23}$ These diverse and useful applicability of PBAs make them 
appropriate potential candidates for battery applications. One common feature for the reported PBAs is the three-dimensional framework determined by the six-fold coordinated precursor, which leads us to consider the possibility of tuning the inherent six-fold coordinated cyanide functional group to develop a different type of PBAs having four-fold tetracyano coordination.

In this study, we designed and synthesized a new family of cyanide linker-based PBAs by using four-fold coordinated tetracyanonickelate. In contrast to previously reported threedimensional PBAs with six-fold coordinated cyanide linkers, we designed MOFs built with four-fold coordinated linkers that were named as four-fold PBAs (FF-PBAs) by using tetracyanonickelate. In addition, we further investigated the electrochemical properties of these innovative FF-PBAs as cathode materials for Li-ion batteries (LIBs), and found them to be extremely electrochemically stable. We believe that this study will inspire the design of innovative MOFs and electrode materials for electrochemical applications.

\section{Results and discussion}

Morphologies of the formed FF-PBAs were observed by scanning electron microscopy (SEM) as shown in Fig. 1a and S1 (ESI $\dagger$ ). Plate-like structures were clearly observed for these products, excluding $\mathrm{Ni}\left[\mathrm{Ni}(\mathrm{CN})_{4}\right](\mathrm{Ni} / \mathrm{Ni})$ and $\mathrm{Ni} / \mathrm{Zn}$. Consistent elements in each product were qualitatively demonstrated by the energydispersive X-ray EDX elemental mapping and spectra (Fig. 1b, S1 and S2 $\dagger$ ), displaying uniformly distributed elements over- through each nanoparticle. This result was further verified by the XRF spectra (Fig. S3 $\dagger$ ), where the corresponding consistent elements were clearly displayed. The layered crystal structures of the FF-PBAs are shown in Fig. 1c and d; it is evident that the cyano linkers alternatively bonded with $\mathrm{Ni}$ and counter transition metal ions, expanding in two-dimensional space and forming a stacked layered crystal structure. However, $\mathrm{Ni} / \mathrm{Ni}$ and $\mathrm{Ni} / \mathrm{Zn}$ displayed particle-shaped products with sizes of $\sim 20 \mathrm{~nm}$ and $\sim 300 \mathrm{~nm}$, respectively. Further studies on the crystallization processes of these two FF-PBAs are needed. The crystal structures of the as-prepared FF-PBAs exhibit characteristic diffraction peaks with high intensities in the XRD patterns (Fig. 1e and S4 $\dagger$ ). The cyano functional groups in the FF-PBAs were further verified by Raman and FT-IR spectroscopies (Fig. 1f, g, S5 and S6 $\dagger$ ). The cyano bridges corresponding to the absorption peak at $\sim 2120 \mathrm{~cm}^{-1}$ in the FT-IR spectra were similar to the cyano linkers in six-fold coordinated PBAs, and were attributed to the in-plane vibrations of the metal-carbonnitrogen bond. ${ }^{17,24}$ The Raman diffraction peak of $\mathrm{C} \equiv \mathrm{N}$ was also affected by the ambient coordinated transition metal ions. Different valence states and transition metal ion species led to a shift of the $\mathrm{C} \equiv \mathrm{N}$ Raman absorption (Fig. S5 $\dagger$ ). In addition, the presence of both weakly bonded and coordinated water molecules was detected by the appearance of $\mathrm{O}-\mathrm{H}$ stretching bands above and below $3500 \mathrm{~cm}^{-1}$ in the FT-IR spectrum (Fig. S6 $\dagger$ ), respectively. ${ }^{25} \mathrm{Ni} / \mathrm{Cu}, \mathrm{Ni} / \mathrm{Co}$, and $\mathrm{Ni} / \mathrm{Zn}$ exhibited negligible $\mathrm{O}-\mathrm{H}$ peaks, suggesting the presence of only a small amount of absorbed water molecules. This result was further verified by the thermal-stability measurements using thermogravimetric
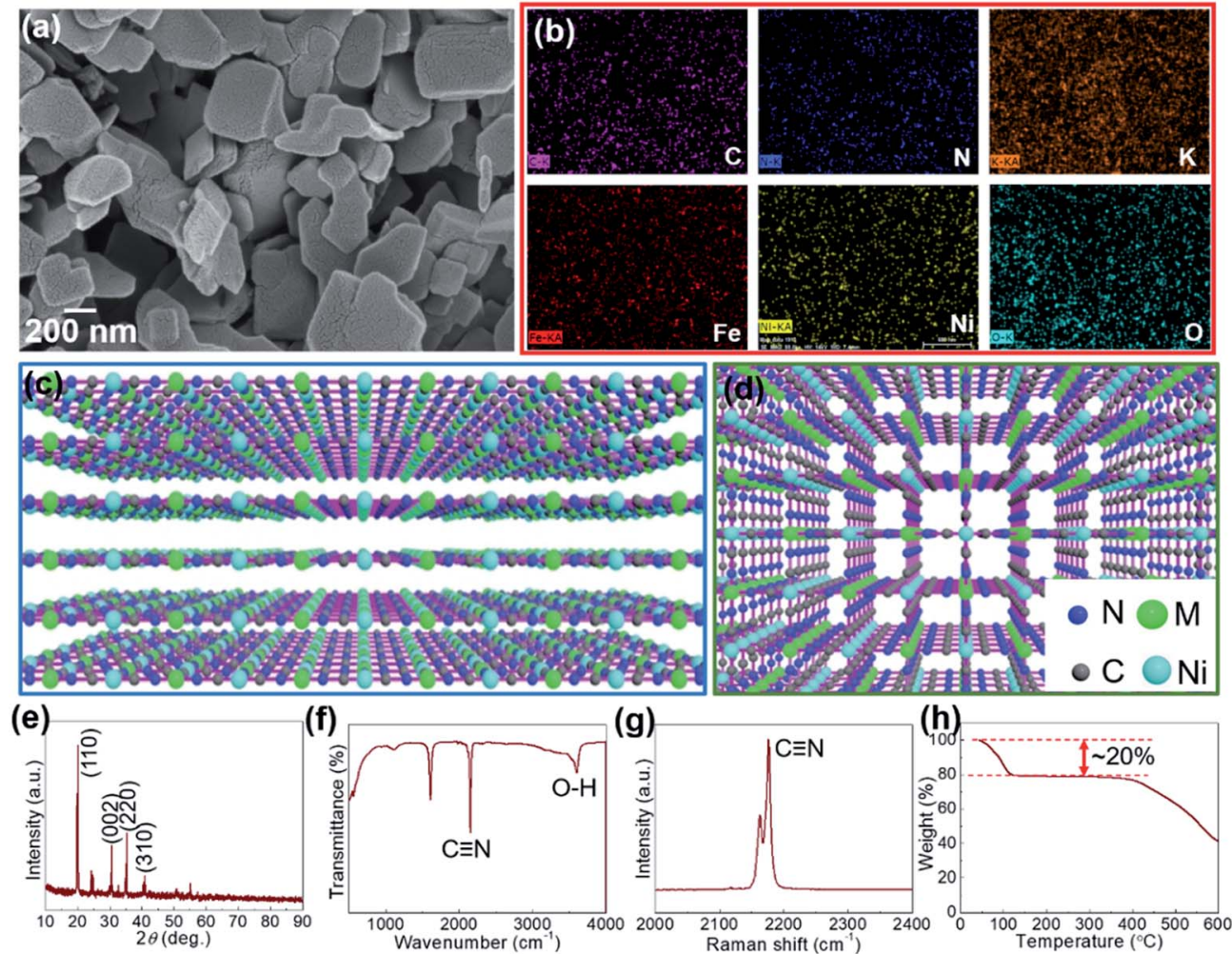

Fig. 1 (a) SEM image, (b) EDX mapping of Ni/Fe ${ }^{2+}$, three dimensional representation of Ni/M(transition metal ions) (c) side view and (d) top view, (e) XRD, (f) FT-IR, (g) Raman, and (h) TGA spectra of $\mathrm{Ni} / \mathrm{Fe}^{2+}$. 
analysis TGA (Fig. S7 $\uparrow$ ); the TGA curves of the three samples showed a slightly drop in the initial stages (low-temperature range). All FF-PBAs were found to be stable until $400{ }^{\circ} \mathrm{C}$, although evaporation of different amounts of water molecules for certain samples was observed owing to the absorbed and coordinated water inside the products.

The layered crystal structures were further studied by transmission electron microscopy (TEM, Fig. 2) for representative $\mathrm{Ni} / \mathrm{Fe}^{2+}$ and $\mathrm{Ni} / \mathrm{Fe}^{3+}$ having the counter transition metal ions with different valence states. The uniform distribution of consistent elements for both $\mathrm{Ni} / \mathrm{Fe}^{2+}$ and $\mathrm{Ni} / \mathrm{Fe}^{3+}$ was further confirmed by EDX mapping (Fig. $2 b$ and d). Furthermore, the expected two-dimensional crystal structures could be clearly observed in Fig. 2e and g, where two-dimensional (2D) films with sizes over $200 \mathrm{~nm}$ and $500 \mathrm{~nm}$ are shown for $\mathrm{Ni} / \mathrm{Fe}^{2+}$ and $\mathrm{Ni} / \mathrm{Fe}^{3+}$, respectively. It is worth noting that the present $2 \mathrm{D}$ materials constructed with transition metal ions are mainly metal sulfides that have complicated and expensive synthetic processes. However, we used relatively low-cost raw materials for the wet chemical approach in aqueous solution at room temperature, and successfully synthesized large-scale 2D PBAs. This result is expected to inspire further studies on using FFPBAs for diverse 2D material-based electronic devices. There is however one possible issue relating to the FF-PBAs, i.e., the lamination behavior caused during the separation of the synthesized products from the aqueous bath on drying, considering the different morphologies in the SEM and TEM images. Thus, Ni/Ni and Ni/Zn with sphere-like morphologies were expected because of aggregation during drying. The wellcrystallized features for $\mathrm{Ni} / \mathrm{Fe}^{2+}$ and $\mathrm{Ni} / \mathrm{Fe}^{3+}$ were attributed to the oriented lattice with a spacing of $0.4 \mathrm{~nm}$ for $\mathrm{Ni} / \mathrm{Fe}^{2+}$ and $0.41 \mathrm{~nm}$ for Ni/Fe ${ }^{3+}$ and Fast Fourier Transform (FFT) patterns corresponding to a polycrystalline nature. In summary, either trivalent $\mathrm{Fe}^{3+}$ or bivalent $\mathrm{Fe}^{2+}$ showed negligible effect on the final crystal structures in the tetrahexacyanonickelate-based FFPBAs. In other words, the final crystal structure of FF-PBAs was mainly determined by the in-plane four-fold coordinated precursor e.g., $\mathrm{Ni}(\mathrm{CN})_{4}{ }^{2-}$.

The desired molecular formulae of the as-prepared products were $\quad \mathrm{K}_{0.65} \mathrm{Ni}\left[\mathrm{Ni}(\mathrm{CN})_{4}\right]_{1.25}, \quad \mathrm{~K}_{0.09} \mathrm{Fe}^{2+}\left[\mathrm{Ni}(\mathrm{CN})_{4}\right]_{0.78}, \quad \mathrm{~K}_{0.2^{-}}$ $\mathrm{Fe}^{3+}\left[\mathrm{Ni}(\mathrm{CN})_{4}\right]_{1.26}, \quad \mathrm{~K}_{0.2} \mathrm{Co}\left[\mathrm{Ni}(\mathrm{CN})_{4}\right]_{0.85}, \quad \mathrm{~K}_{0.05} \mathrm{Mn}\left[\mathrm{Ni}(\mathrm{CN})_{4}\right]_{0.81}$, $\mathrm{K}_{0.13} \mathrm{Zn}\left[\mathrm{Ni}(\mathrm{CN})_{4}\right]_{1.42}, \mathrm{~K}_{0.23} \mathrm{Cu}\left[\mathrm{Ni}(\mathrm{CN})_{4}\right]_{0.92}$, respectively, based on the X-ray fluorescence (XRF) results. The specific calculation was performed by normalizing the stoichiometric number of coordinated transition metal ions (i.e., $\mathrm{Ni}^{2+}, \mathrm{Fe}^{2+}, \mathrm{Fe}^{3+}, \mathrm{Co}^{2+}$, $\mathrm{Mn}^{2+}, \mathrm{Zn}^{2+}$, and $\mathrm{Cu}^{2+}$ ) in each deduced molecular formula (see $\mathrm{ESI} \dagger$ for detailed calculation). Absorbed water molecules were not shown, as they were sensitive to the humidity and temperature of the ambient environment.

The bonding nature of $\mathrm{Ni} / \mathrm{Fe}^{2+}$ was analyzed based on the XPS spectra, where the wide-survey image (Fig. 3a) clearly showed the binding nature between each element as that of other FF-PBAs (Fig. S8 $\dagger$ ). The cyanide bond in $\mathrm{Ni} / \mathrm{Fe}^{2+}$ was further demonstrated in the XPS spectra (Fig. 3b and c). The residual water molecules were evident in the deconvoluted $\mathrm{O} 1 \mathrm{~s}$ spectra (Fig. 3d). A systematic comparison of the deconvoluted $\mathrm{C} 1 \mathrm{~s}, \mathrm{~N}$ 1s, $\mathrm{O}$ 1s, and Ni 2p spectra is shown in Fig. S9, $\dagger$ where the $\mathrm{C}$ 1s and $\mathrm{N}$ 1s spectra were obtained at the same binding energies (284.6 eV and $398.1 \mathrm{eV}$, respectively). This demonstrated a good compatibility of the cyanide bridge for multiple transition metal ions without any obvious distortion. However, the $\mathrm{O} 1 \mathrm{~s}$ spectrum greatly depended on the existed state of the absorbed water molecules, exhibiting a slight shift of the binding energy in XPS spectra (Fig. S9c $\dagger$ ). The $\mathrm{Ni}^{2+}$ node in $\mathrm{Ni}$ / $\mathrm{Fe}^{2+}$ is shown in Fig. 3e, where a pure $\mathrm{Ni}^{2+}$ phase was detected. The common $\mathrm{Ni}^{2+}$ node showed almost no shift under different
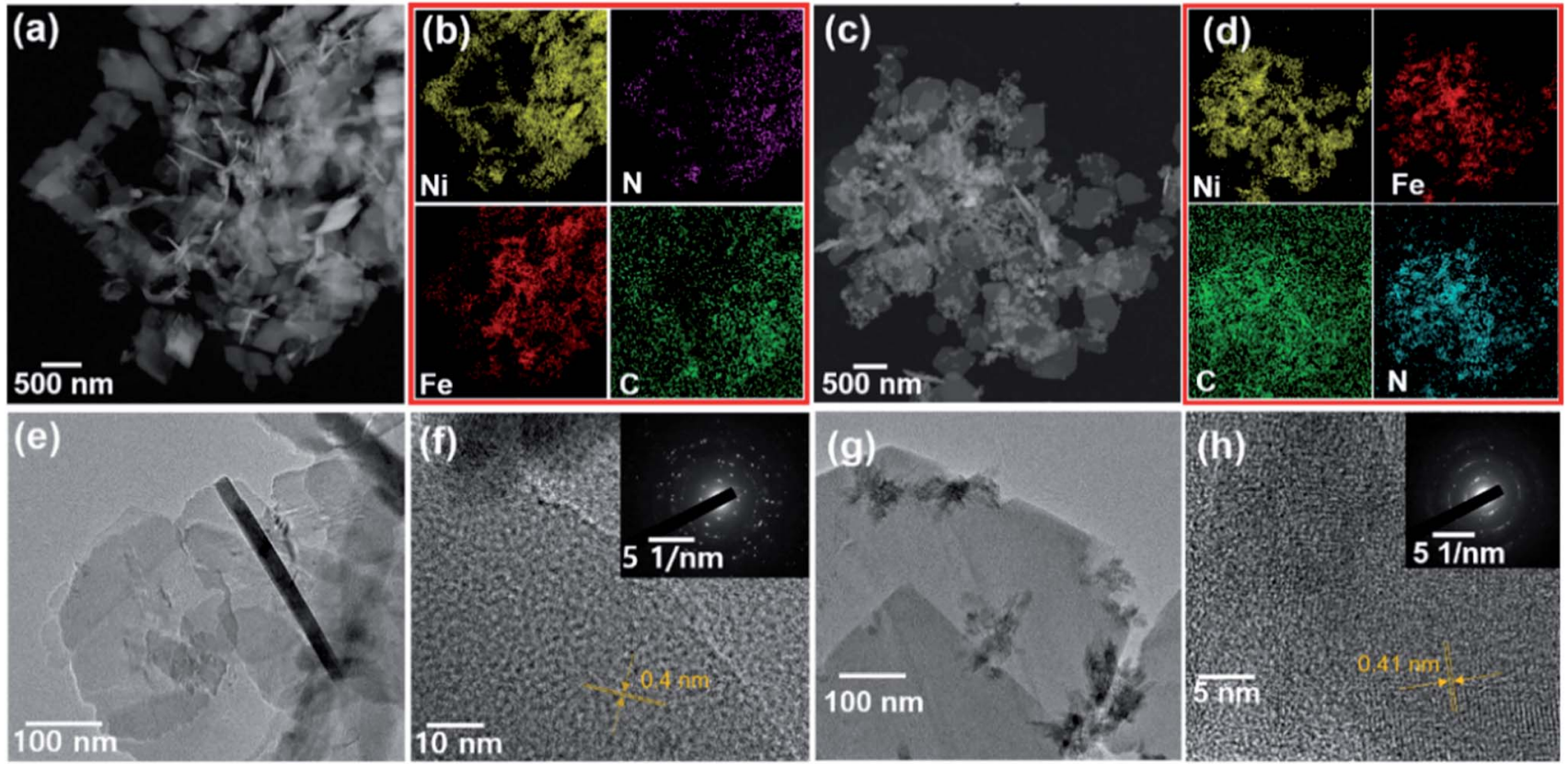

Fig. 2 (a) STEM, (b) EDX mapping, (e) TEM, and (f) HRTEM of Ni/Fe ${ }^{2+}$. (c) STEM, (d) EDX mapping, (g) TEM, and (h) HRTEM of Ni/Fe ${ }^{3+}$. Insets exhibit the diffraction patterns. 

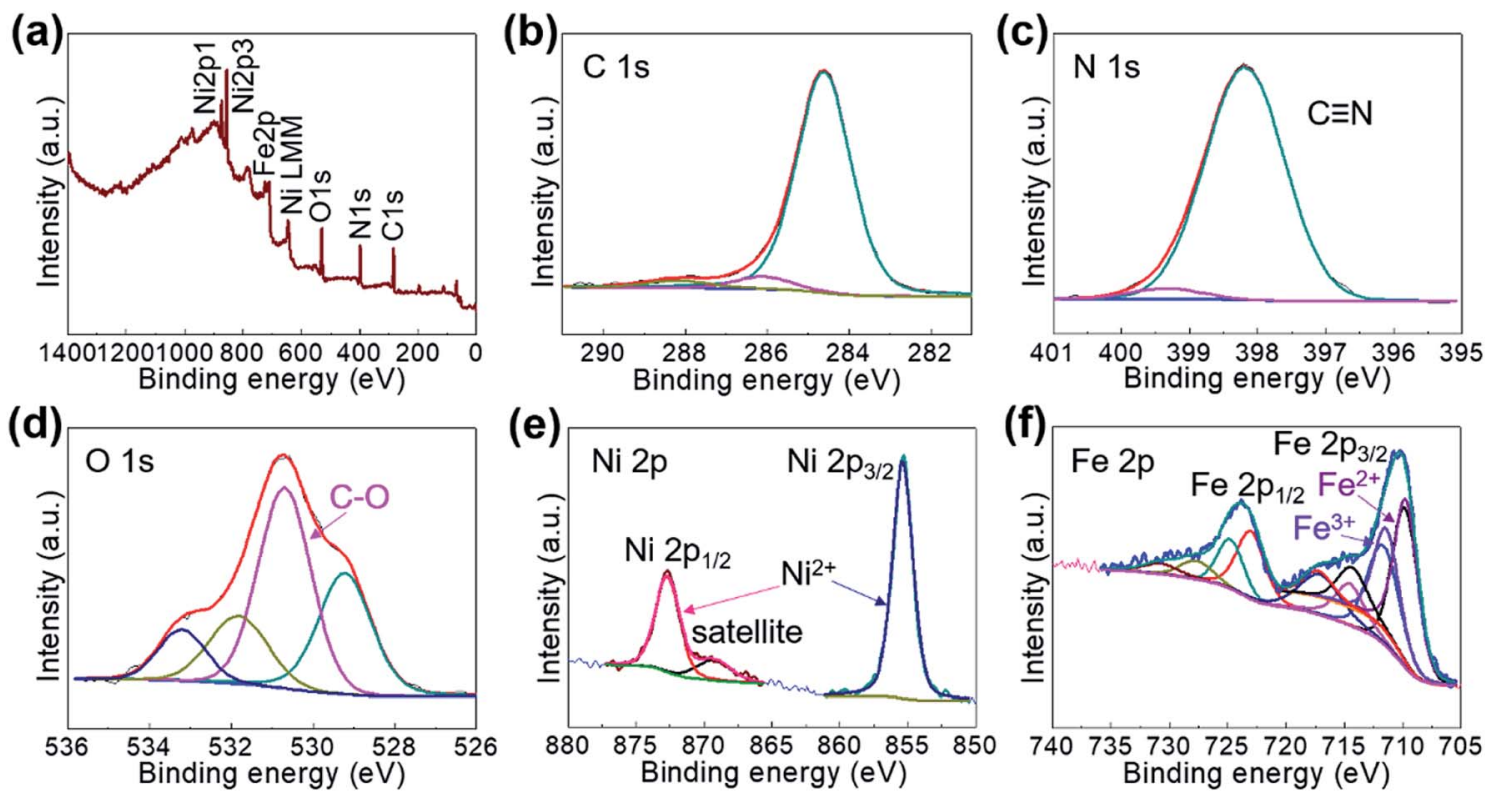

Fig. 3 XPS spectra of (a) wide survey, (b) $\mathrm{C} 1 \mathrm{~s}$, (c) $\mathrm{N} 1 \mathrm{~s}$, (d) $\mathrm{O} 1 \mathrm{~s}$, (e) $\mathrm{Ni} 2 \mathrm{p}$, and (f) $\mathrm{Fe} 2 \mathrm{p}$ of $\mathrm{Ni} / \mathrm{Fe}^{2+}$.

coordination environments where various transition metal ions were bonded (Fig. S9d $\dagger$ ). The deconvoluted Fe 2p XPS spectra of $\mathrm{Ni} / \mathrm{Fe}^{2+}$ (Fig. 3f) suggested a coexistence of $\mathrm{Fe}^{2+}$ and $\mathrm{Fe}^{3+}$, owing to the electron transfer through the cyano bridge or coordination to the $\mathrm{O}$ or $\mathrm{N}$ from environment, which is in consistent with the transition metal ions in conventional PBAs. ${ }^{26}$ These multiple valence states have also been observed in other FFPBAs (Fig. S10†) excluding the deconvoluted Zn 2p spectrum, which showed a relatively pure phase.

The Ni K-edge X-ray absorption near-edge structure (XANES) spectra for the representative $\mathrm{Ni} / \mathrm{Fe}^{2+}$ and $\mathrm{Ni} / \mathrm{Ni}$ are depicted in Fig. 4. It could be clearly observed that the line shapes of the $\mathrm{Ni}$ K-edge XANES spectra for $\mathrm{Ni} / \mathrm{Fe}^{2+}$ and $\mathrm{Ni} / \mathrm{Ni}$ were analogous, typically showing that the electronic and local structures of $\mathrm{Ni}^{2+}$ were not changed. The position of the adsorption edge reflects that the oxidation state of the $\mathrm{Ni}$ ions is I. $^{27,28}$

The electrochemical properties of $\mathrm{Ni} / \mathrm{Fe}^{2+}$ as a cathode material of LIBs were measured in half-cells. Cyclic voltammetry (CV) curves were measured in the potential window of 2.2-4.5 V vs. $\mathrm{Li}^{+} / \mathrm{Li}$, where distortions were absent and raised redox peaks were observed with hysteresis phenomenon (Fig. 5a). The

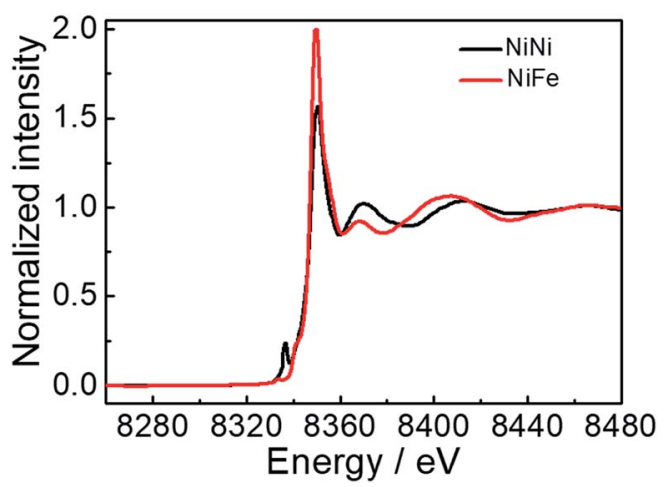

Fig. 4 XANES spectra at $\mathrm{Ni} \mathrm{K}$-edge collected from $\mathrm{Ni} / \mathrm{Ni}$ and $\mathrm{Ni} / \mathrm{Fe}^{2+}$. subsequent repeated charge/discharge cycling tests were also performed in such a potential window. The rate performance of $\mathrm{Ni} / \mathrm{Fe}^{2+}$ was measured at various current densities of 100,200 , $400,600,800$, and $1000 \mathrm{~mA} \mathrm{~g}^{-1}$. The capacity retention at $1000 \mathrm{~mA} \mathrm{~g}^{-1}$ was $43 \%$ and a good capacity recovery was achieved (Fig. 5b) with constant charge/discharge behaviors (Fig. 5d). The repeated charge/discharge cycling test was performed at $100 \mathrm{~mA} \mathrm{~g}^{-1}$, displaying a competitive discharge capacity of $137.9 \mathrm{~mA} \mathrm{~h} \mathrm{~g}{ }^{-1}$ for $\mathrm{Ni} / \mathrm{Fe}^{2+}$ at the first $20^{\text {th }}$ cycle (Fig. 5c) with constant charge/discharge behaviors (Fig. 5e), which was considerably superior to that of most other PBAs used as electrode materials. ${ }^{9,29,30}$ In a controlled experiment, we also performed the repeated charge/discharge cycling tests for other FF-PBAs at the same conditions. It was found that $\mathrm{Ni} / \mathrm{Fe}^{2+}$

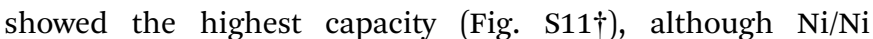
exhibited transient discharge values greater than $150 \mathrm{~mA} \mathrm{~h} \mathrm{~g}{ }^{-1}$. These charge/discharge values of FF-PBAs show a significant dependence of the final electrochemical properties on the reactants.

Long-term charge/discharge stability of the electrode material is critical for practical applications. Therefore, we further subjected the $\mathrm{Ni} / \mathrm{Fe}^{2+}$ electrode system to a long-term repeated charge/discharge measurement at $1000 \mathrm{~mA} \mathrm{~g}^{-1}$. A prominent stable charge/discharge process was established with an initial lithiation capacity of $56.8 \mathrm{~mA} \mathrm{~h} \mathrm{~g}{ }^{-1}$ (Fig. 5f). After the initial activation process, an improved capacity of $64.5 \mathrm{~mA} \mathrm{~h} \mathrm{~g}{ }^{-1}$ as compared with that in the initial range and an extremely high coulombic efficiency of $98.8 \%$ were obtained. After the longterm cycling test, a capacity reserve of $86.1 \%$ (as compared with the highest capacity value of $71 \mathrm{~mA} \mathrm{~h} \mathrm{~g}^{-1}$ ) was achieved (60.3 $\mathrm{mA} \mathrm{h} \mathrm{g}^{-1}$ at the $5000^{\text {th }}$ cycle). This long-term repeated charge/discharge cycling test sufficiently demonstrated the stability of the layered $\mathrm{Ni} / \mathrm{Fe}^{2+}$ PBA when used as a cathode material of LIBs. Further characterization of the highperformance $\mathrm{Ni} / \mathrm{Fe}^{2+}$ system was achieved by electrochemical 


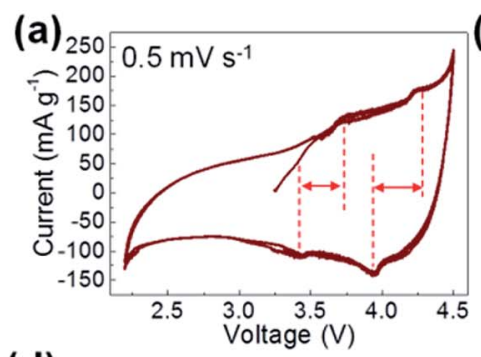

(d) 4

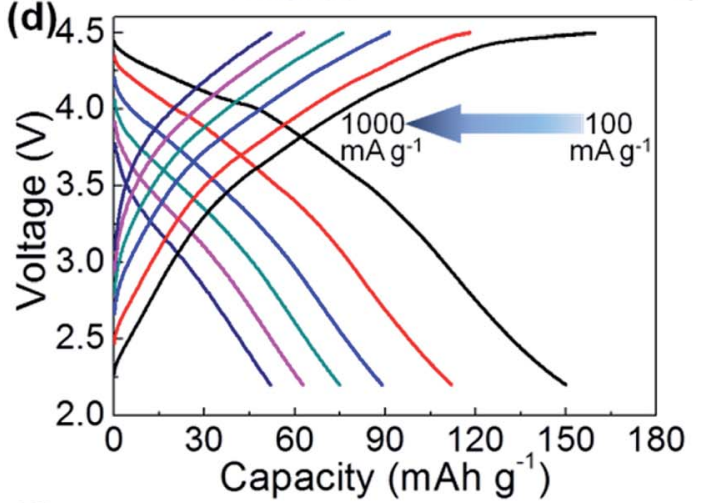

(f) 100

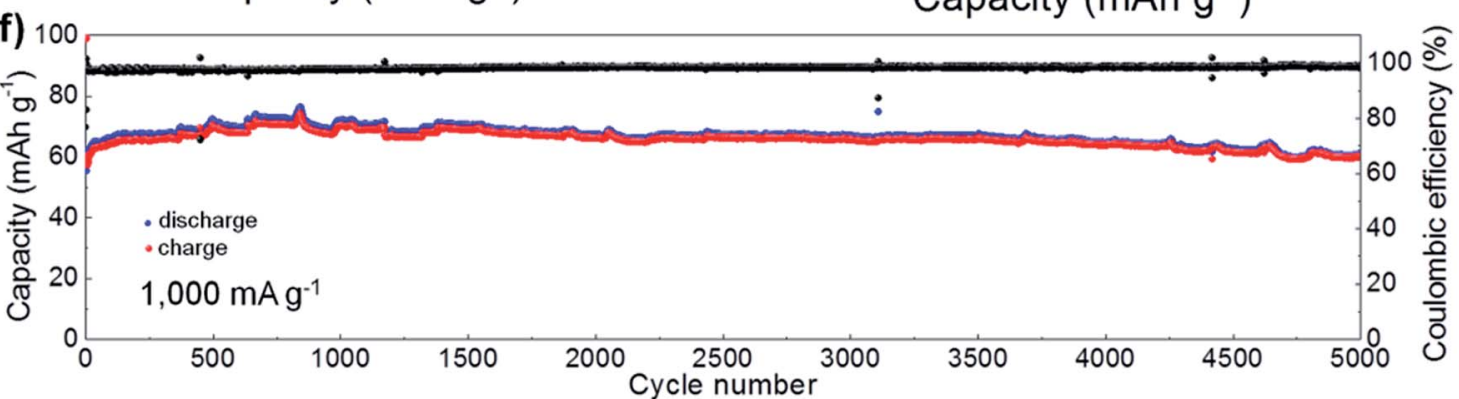

Fig. 5 (a) CV curve, (b) rate-performance, (c) repeated charge/discharge cycling measurement at $100 \mathrm{~mA} \mathrm{~g}^{-1}$ of $\mathrm{Ni} / \mathrm{Fe}^{2+}$. Representative charge/ discharge voltage profiles of (d) rate performance and (e) cycling measurements at a current density of $100 \mathrm{~mA} \mathrm{~g}^{-1}$. (f) Long-term consecutive charge/discharge cycling test at $1000 \mathrm{~mA} \mathrm{~g}^{-1}$ of Ni/Fe ${ }^{2+}$.

impedance spectroscopy (EIS). The charge-transfer impedance of $\mathrm{Ni} / \mathrm{Fe}^{2+}$ was obtained by the Nyquist curve (Fig. S12 $\dagger$ ), where the depressed semi-circle (charge-transfer) was connected to an oblique line (Warburg impedance). A charge-transfer impedance of $\sim 200 \mathrm{ohm}$ was observed at the intercept with $Z^{\prime}$ axis.

The mechanism for the storage of $\mathrm{Li}^{+}$by $\mathrm{Ni} / \mathrm{Fe}^{2+}$ was analyzed by $\mathrm{CV}$ scans at different scan rates $\left(0.5-2.5 \mathrm{mV} \mathrm{s}^{-1}\right)$ within the same potential window of $2.2-4.5 \mathrm{~V}$ vs. $\mathrm{Li}^{+} / \mathrm{Li}$ (Fig. 6a). The curves obtained at all scan rates displayed a well-preserved shape and no obvious distortion. To further disclose this Liion storage feature, the dependence of the response current $(i)$ on the scan rate $(v)$ was modeled by the following power law: $:^{31,37}$

$$
i=a v^{b}
$$

It is expected to afford a straight line with slope $b$ by fitting $\log (i) v s . \log (v) ; b=0.5$ corresponds to diffusion-controlled Liion storage, indicating a faradaic electrochemical reaction, while $b=1.0$ corresponds to the capacitive Li-ion storage process. Here, $b$-values between 0.5 and 1.0 obtained from the deviated fitting line (Fig. 6b) indicating the co-existence of diffusion- and surface-controlled (capacitive) Li-ion storage processes. The contribution ratios of these storage mechanisms were calculated by deriving eqn (1) as:

$$
i=k_{1} v+k_{2} v^{1 / 2}
$$

where $k_{1} v$ represents the contribution of the $b=1$ case, and $k_{2} v^{1 / 2}$ represents the contribution of the $b=0.5$ case. The obtained results are presented in Fig. $6 \mathrm{c}$, showing that at $0.5 \mathrm{mV} \mathrm{s}^{-1}, 62 \%$ of the total capacity corresponds to the diffusion-controlled $\mathrm{Li}^{+}$ storage. This contribution decreased with the increasing scan rate $\left(46 \%\right.$ at $\left.2.5 \mathrm{mV} \mathrm{s}^{-1}\right)$, indicating an increased polarization of the electrode at higher scan rates.

Further in-depth study on the charge/discharge mechanism was conducted by ex situ XRD. During a charge/discharge process, the characteristic peaks of $\mathrm{Ni} / \mathrm{Fe}^{2+}$ at diverse discharge states were well preserved in the XRD spectra (Fig. 7), demonstrating structural integrity. However, an obvious decrease in the intensity of the (110) peak accompanied by a slight shift toward lower diffraction angles indicated the expansion of layered $\mathrm{Ni} / \mathrm{Fe}^{2+}$ due to the insertion of $\mathrm{Li}^{+}$. Accordingly, the Li species in the $\mathrm{Ni} / \mathrm{Fe}^{2+}$ cathode materials at various cutoff potentials was recognized in the ex situ XRD spectra. It is interesting that the detected Li species in these 
(a) 800

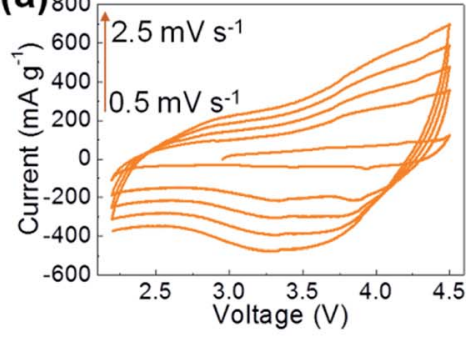

(b)

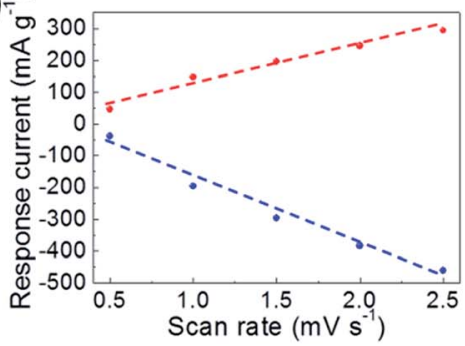

(c)

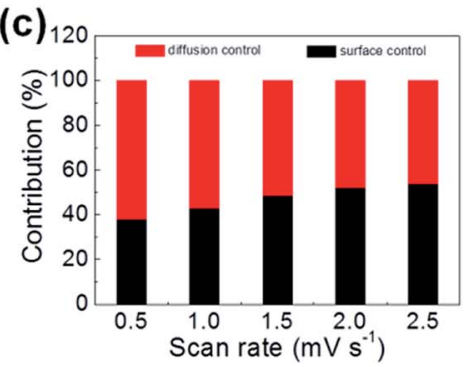

Fig. 6 Electrochemical characterization and analysis for $\mathrm{Ni} / \mathrm{Fe}^{2+}$ : (a) CV curves at different scan rates, (b) response current at different scan rates measured from (a) and the fitting dash line, (c) contribution ratios for capacity at various scan rates.

samples was elemental $\mathrm{Li}^{32-36}$ as it allowed us to peruse the electrochemical mechanism of the $\mathrm{Ni} / \mathrm{Fe}^{2+} \mathrm{PBA}$ in the $\mathrm{Li}$-ion storage process. When $\mathrm{Li}^{+}$ions from the electrolyte were inserted into the interlayers of $\mathrm{Ni} / \mathrm{Fe}^{2+}$, they could be reduced in situ by the incoming electrons instead of forming compounds with the host material. Therefore, the electrochemical reaction of the discharge process can be written as $\mathrm{Li}^{+}+\mathrm{e}^{-}=\mathrm{Li}$. Hence, it can be concluded that the Ni/ $\mathrm{Fe}^{2+} \mathrm{PBA}$ served as a Li host during the electrochemical process, which may also explain the quasirectangular shaped $\mathrm{CV}$ curves. This Li-ion storage mechanism is quite similar to that of the conventional PBAs in metal ion capacitors. ${ }^{23}$

\section{Experimental}

\section{Material preparation}

The FF-PBAs were synthesized by a co-precipitation method at room temperature by the simultaneous dropwise addition of $100 \mathrm{~mL}$ of $0.1 \mathrm{M} \mathrm{FeSO}_{4}, \mathrm{MnSO}_{4}, \mathrm{NiSO}_{4}, \mathrm{ZnSO}_{4}, \mathrm{CuSO}_{4}, \mathrm{CoSO}_{4}$, $\mathrm{FeCl}_{3}$ (Sigma-Aldrich) and $100 \mathrm{~mL}$ of $0.01 \mathrm{M} \mathrm{K}_{2}\left[\mathrm{Ni}(\mathrm{CN})_{4}\right]$ (SigmaAldrich) to $200 \mathrm{~mL}$ of $\mathrm{H}_{2} \mathrm{O}$. Precipitates were formed immediately upon dropwise introduction of the solutions. The formed precipitates were separated and rinsed with deionized water several times to remove the impurity ions (such as $\mathrm{K}^{+}$). They were subsequently dried in a vacuum oven at $60^{\circ} \mathrm{C}$.

\section{Physical characterization}

X-ray diffraction (XRD, D8-Advance diffractometer with $\mathrm{Cu} \mathrm{K} \alpha$ radiation at a fixed incident angle of $2^{\circ}$ ) was used for structural studies. The surface chemical nature of the formed FF-PBAs was studied by X-ray photoelectron spectroscopy (XPS, PHI 5000 VersaProbe). Ni K-edge X-ray absorption near-edge spectra (XANES) were recorded on the CRG-FAME (BM30B) beamline. The energy of the incident radiation was selected using a pair of $\mathrm{Si}(220)$ crystals. Raman spectroscopy (inVia Raman microscope) and Fourier transform infrared (FT-IR, Nicolet iS50) spectroscopy were used for the detection of the cyano functional groups in the products. The morphologies and constitutions were investigated by field emission-scanning electron microscopy (FE-SEM, SUPRA 55VP), transmission electron microscopy (TEM, Tecnai F20), and energy-dispersive X-ray spectroscopy (EDX). Percentages of the constitution elements for each sample
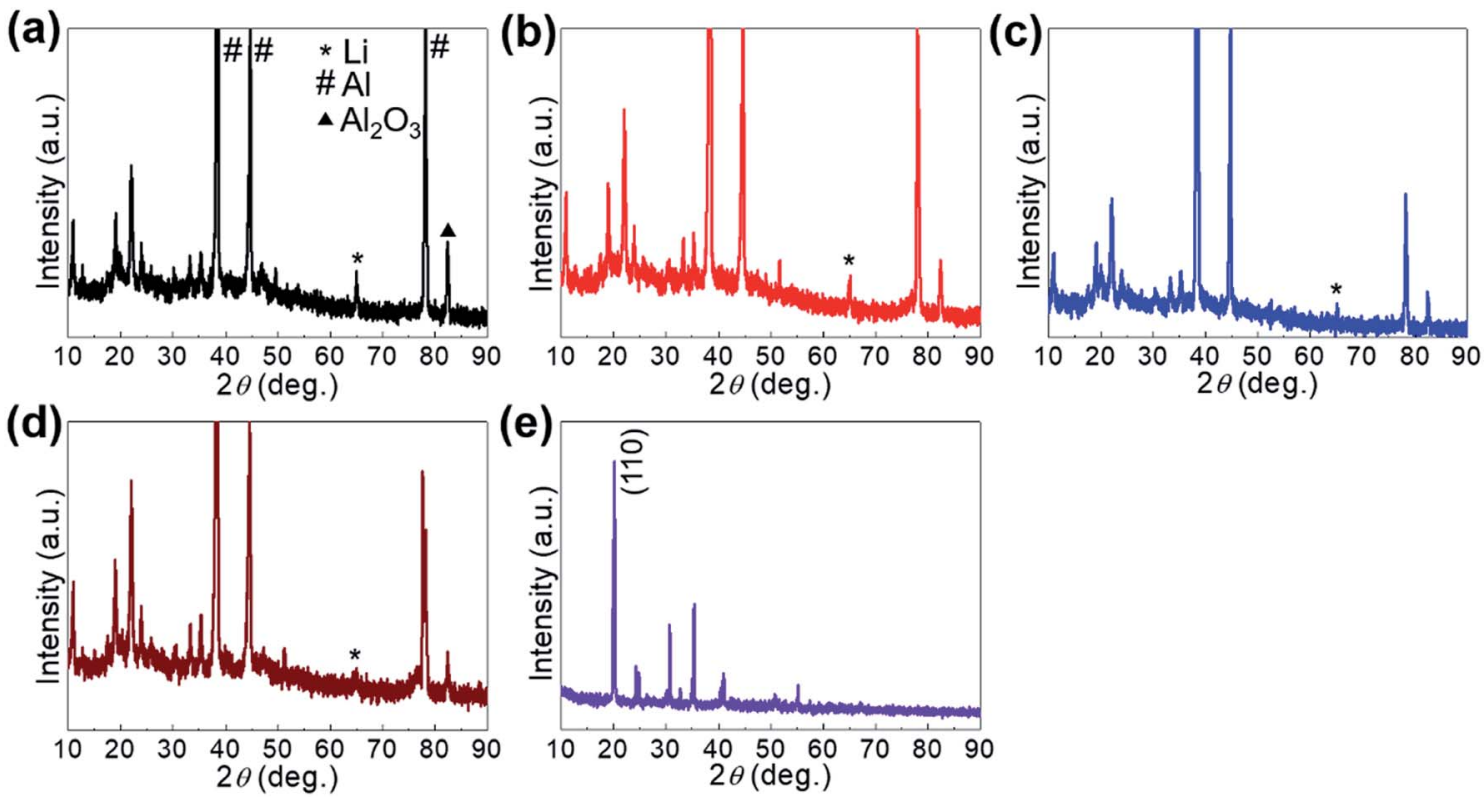

Fig. 7 Ex situ XRD characterizations collected from Ni/Fe ${ }^{2+}$ at charge stages of (a) 2.2, (b) 3.0, (c) 3.7, and (d) 4.5 V. (e) XRD spectra of original Ni/ $\mathrm{Fe}^{2+}$. 
were determined from X-ray fluorescence (XRF, ZSX-PRIMUS) studies. Thermogravimetric analysis (TGA, SDT) was performed under $\mathrm{N}_{2}$ flow from room temperature to $600{ }^{\circ} \mathrm{C}$ with a temperature ramp of $10{ }^{\circ} \mathrm{C} \mathrm{min}^{-1}$.

\section{Preparation of electrodes}

A slurry containing FF-PBAs, carbon black (Super P Li), and poly(vinylidene)difluoride (PVDF) in a mass ratio of $7: 2: 1$ was prepared by manually grinding the mixed powders and subsequently dispersing them in $N$-methyl-2-pyrrolidinone (NMP) in a manner similar to previously published reports. In addition, prior to the injection of NMP, the mixed powders were sufficiently dried overnight in a vacuum oven at $80{ }^{\circ} \mathrm{C}$ and were weighed before and after vacuum drying to ensure the water removal.

\section{As a cathode of LIBs}

A working electrode with a mass loading of $\sim 3 \mathrm{mg} \mathrm{cm}^{-2}$ was prepared by spreading the slurry on an $\mathrm{Al}$ foil current collector, followed by drying it overnight in a vacuum oven at $60^{\circ} \mathrm{C}$.

\section{Electrochemical characterization}

In order to perform electrochemical measurements, half-cells were prepared using FF-PBA active materials (as the working electrode) and sufficient Li metal flooded with $1.0 \mathrm{M} \mathrm{LiPF}_{6}$ in a 1: 1 mixture (by volume) of ethylene carbonate and diethylene carbonate in an argon-filled glove box with water content less than $5 \mathrm{ppm}$.

Cyclic voltammetry (CV) measurements were performed with an electrochemical workstation (WBCS3000, Wonatech, Korea) in the potential range of $2.2-4.5 \mathrm{Vvs} . \mathrm{Li}^{+} / \mathrm{Li}$ at a scan rate of $0.5 \mathrm{mV} \mathrm{s}^{-1}$. Galvanostatic charge/discharge cycling measurements were performed between $2.2-4.5 \mathrm{~V}$ vs. $\mathrm{Li}^{+} / \mathrm{Li}$. Unless otherwise noted, all the current densities and specific capacities in this report were calculated based on the weight of the FFPBAs.

\section{Ex situ characterization}

The ex situ characterizations of the $\mathrm{Ni} / \mathrm{Fe}^{2+}$ system discharged to various potentials $(2.2,3.0,3.7$, and $4.5 \mathrm{~V})$ were performed by XRD. The cathodes containing $\mathrm{Ni} / \mathrm{Fe}^{2+}$ were de-assembled from half-cells, followed by thorough rinsing with ethanol and drying in a vacuum oven at $60^{\circ} \mathrm{C}$.

\section{Conclusions}

In summary, several tetracyano-based FF-PBAs with layered crystal structures that were quite different from the conventional hexacyano-based PBAs with framework crystal structures, were synthesized. TEM revealed the two-dimensional features of $\mathrm{Ni} / \mathrm{Fe}^{2+}$ and $\mathrm{Ni} / \mathrm{Fe}^{3+}$. These innovative layered materials are expected to inspire further study of two-dimensional materials. $\mathrm{Ni} / \mathrm{Fe}^{2+}$ exhibited high stability during repeated charge/ discharge cycling as a cathode in LIBs, with a capacity of $60.3 \mathrm{~mA} \mathrm{~h} \mathrm{~g}^{-1}$ and coulombic efficiency of $98.8 \%$ at the $5000^{\text {th }}$ cycle. A good rate capability was achieved; the capacity of $86.1 \%$ was preserved at $1000 \mathrm{~mA} \mathrm{~g}^{-1}$ as compared with that at $100 \mathrm{~mA} \mathrm{~g}^{-1}$. The design of FF-PBAs outlined in the present report is expected to pave the path toward the development of low-cost and environment-friendly LIBs in the future.

\section{Conflicts of interest}

There are no conflicts to declare.

\section{Acknowledgements}

This research was supported by Korea Institute of Science and Technology Future Resource Program (2E29400). Furthermore, the financial supports of the Future Material Discovery Program (2016M3D1A1027666), and the Basic Science Research Program (2017R1A2B3009135) through the National Research Foundation of Korea are appreciated.

\section{References}

1 C. Xuan, J. Wang, W. Xia, Z. Peng, Z. Wu, W. Lei, K. Xia, H. L. Xin and D. Wang, ACS Appl. Mater. Interfaces, 2017, 9, 26134.

2 M. Shokouhimehr, E. S. Soehnlen, J. Hao, M. Griswold, C. Flask, X. Fan, J. P. Basilion, S. Basu and S. D. Huang, J. Mater. Chem., 2010, 20, 5251.

3 M. Shokouhimehr, E. S. Soehnlen, A. Khitrin, S. Basu and S. D. Huang, Inorg. Chem. Commun., 2010, 13, 58.

4 L. Han, X. Y. Yu and X. W. Lou, Adv. Mater., 2016, 28, 4601. 5 Y. Jiang, A. Takahashi, T. Kawamoto, M. Asai, N. Zhang, Z. Lei, Z. Zhang, K. Kojima, K. Imoto, K. Nakagawa, S. Ohkoshi and T. Nakamura, Chem. Commun., 2018, 54, 11961.

6 S.-H. Yu, M. Park, H. S. Kim, A. Jin, M. Shokouhimehr, T.-Y. Ahn, Y.-W. Kim, T. Hyeon and Y.-E. Sung, RSC Adv., 2014, 4, 12087.

7 S.-H. Yu, X. Guo, D. Ling, D. Y. Chung, A. Jin, M. Shokouhimehr, T. Hyeon and Y.-E. Sung, RSC Adv., 2014, 4, 37365.

8 M. Shokouhimehr, S.-H. Yu, D.-C. Lee, D. Ling, T. Hyeon and Y.-E. Sung, Nanosci. Nanotechnol. Lett., 2013, 5, 770.

9 S.-H. Yu, M. Shokouhimehr, T. Hyeon and Y.-E. Sung, ECS Electrochem. Lett., 2013, 2, A39.

10 H.-H. Zou, C.-Z. Yuan, H.-Y. Zou, T.-Y. Cheang, S.-J. Zhao, U. Y. Qazi, S.-L. Zhong, L. Wang and A.-W. Xu, Catal. Sci. Technol., 2017, 7, 1549.

11 J.-G. Wang, Z. Zhang, X. Zhang, X. Yin, X. Li, X. Liu, F. Kang and B. Wei, Nano Energy, 2017, 39, 647.

12 T. Rodenas, I. Luz, G. Prieto, B. Seoane, H. Miro, A. Corma, F. Kapteijn, F. X. L. Xamena and J. Gascon, Nat. Mater., 2015, 14, 48.

13 S. Zhao, Y. Wang, J. Dong, C.-T. He, H. Yin, P. An, K. Zhao, X. Zhang, C. Gao, L. Zhang, J. Lv, J. Wang, J. Zhang, A. M. Khattak, N. A. Khan, Z. Wei, J. Zhang, S. Liu, H. Zhao and Z. Tang, Nat. Energy, 2016, 1, 16184.

14 L. Han, X. Y. Yu and X. W. Lou, Adv. Mater., 2016, 28, 4601. 
15 R. Chen, Y. Huang, M. Xie, Z. Wang, Y. Ye, L. Li and F. Wu, ACS Appl. Mater. Interfaces, 2016, 8, 31669.

16 L. Fan, C. Jia, Y. G. Zhu and Q. Wang, ACS Energy Lett., 2017, 2, 615.

17 K. Zhang, R. S. Varma, H. W. Jang, J.-W. Choi and M. Shokouhimehr, J. Alloys Compd., 2019, 791, 911.

18 P. Nie, J. Yuan, J. Wang, Z. Le, G. Xu, L. Hao, G. Pang, Y. Wu, H. Dou, X. Yan and X. Zhang, ACS Appl. Mater. Interfaces, 2017, 9, 20306.

19 W. Ren, M. Qin, Z. Zhu, M. Yan, Q. Li, L. Zhang, D. Liu and L. Mai, Nano Lett., 2017, 17, 4713.

20 J.-H. Lee, G. Ali, D. H. Kim and K. Y. Chung, Adv. Energy Mater., 2017, 7, 1601491.

21 L. Deng, Z. Yang, L. Tan, L. Zeng, Y. Zhu and L. Guo, Adv. Mater., 2018, 30, 1802510.

22 J. -S. Lee, G. Nam, J. Sun, S. Higashi, H. -W. Lee, S. Lee, W. Chen, Y. Cui and J. Cho, Adv. Energy Mater., 2016, 6, 1601052.

23 Z. Li, K. Xiang, W. Xing, W. C. Carter and Y.-M. Chiang, Adv. Energy Mater., 2015, 5, 1401410.

24 M. Xie, Y. Huang, M. Xu, R. Chen, X. Zhang, L. Li and F. Wu, J. Power Sources, 2016, 302, 7.

25 M. Xie, M. Xu, Y. Huang, R. Chen, X. Zhang, L. Li and F. Wu, Electrochem. Commun., 2015, 59, 91.

26 P. Xiong, G. Zeng, L. Zeng and M. Wei, Dalton Trans., 2015, 44, 16746.
27 D. Wierzbicki, R. Baran, R. Dębek, M. Motak, T. Grzybek, M. E. Gálvez and P. D. Costa, Int. J. Hydrogen Energy, 2017, 42, 23548.

28 A. M. Beale, M. Paul, G. Sankar, R. J. Oldman, C. R. A. Catlow, S. French and M. Fowles, J. Mater. Chem., 2009, 19, 4391.

29 C. H. Li, Y. Nanba, D. Asakura, M. Okubo and D. R. Talham, RSC Adv., 2014, 4, 24955.

30 M. Shokouhimehr, S. H. Yu, D. C. Lee, D. Ling, T. Hyeon and Y.-E. Sung, Nanosci. Nanotechnol. Lett., 2013, 5, 770.

31 L. Shen, H. Lv, S. Chen, P. Kopold, P. A. Aken, X. Wu, J. Maier and Y. Yu, Adv. Mater., 2017, 29, 1700142.

$32 \mathrm{M}$. Wu, Z. Wen, Y. Liu, X. Wang and L. Huang, J. Power Sources, 2011, 196, 8091.

33 K. Zhang, T. H. Lee, H. W. Jang, M. Shokouhimehr and J. W. Choi, Electron. Mater. Lett., 2019, 15, 444.

34 B. Jiang, Y. Zeng, H. Yin, R. Li and F. Pan, Prog. Nat. Sci., 2012, 22, 160.

35 B. Mazinani, M. Kazazi, G. Mobarhan and M. Shokouhimehr, JOM, 2019, 71, 1499.

36 G. Ma, Z. Wen, M. Wu, C. Shen, Q. Wang, J. Jin and X. Wu, Chem. Commun., 2014, 50, 14209.

37 J. Ding, H. Wang, Z. Li, K. Cui, D. Karpuzov, X. Tan, A. Kohandehghan and D. Mitlin, Energy Environ. Sci., 2015, 8, 941. 